\title{
Prevalence of diarrheain under-five children among health extension model and non-model households in Sheko district rural community, Southwest Ethiopia
}

\author{
Teklemichael Gebru ${ }^{1}$, Mohammed Taha ${ }^{2}$, Wondwosen Kassahun ${ }^{3}$ \\ ${ }^{1}$ Department of Public Health, Aman Health Science College, Mizan, Ethiopia \\ ${ }^{2}$ Department of Epidemiology, Jimma University, Jimma, Ethiopia \\ ${ }^{3}$ Department of Biostatistics, Jimma University, Jimma, Ethiopia
}

\section{Email address:}

teklemichaelgebru@gmail.com (T. Gebru), tahamohammed2009@gmail.com (M. Taha), wondkyt@yahoo.com (W. Kassahun)

\section{To cite this article:}

Teklemichael Gebru, Mohammed Taha, Wondwosen Kassahun. Prevalence of Diarrheain Under-Five Children among Health Extension Model and Non-Model Households in Sheko District Rural Community, Southwest Ethiopia. Science Journal of Public Health .

Vol. 1, No. 5, 2013, pp. 230-234. doi: 10.11648/j.sjph.20130105.18

\begin{abstract}
Background: Childhood mortality rates reduction by two-thirds is one of the Millennium Development Goals target. Worldwide diarrheal disease is the second leading cause of death in under-five year'schildren.It is responsible for 1.7 million morbidity and 760, 000 mortality of children every year. In Ethiopia diarrhea kills half million under-five children annually.Around $90 \%$ of diarrheal disease occurs due to poor sanitation, lack of access to clean water supply and inadequate personal hygiene. In Ethiopia healthcare, those factors are included in health extension programme as intervention package, which is introduced in 2002/03. As a strategy of the programme households have been graduated as Model Families by the 16 interventional packages.Objective: To assess prevalence of diarrheal disease in under-five children among health extension model and non-model families in Sheko district rural community, Southwest Ethiopia.Methods: a community based comparative cross-sectional study design was employed from January 31 to February29/2012 in Sheko district. A stratified multi-stage simple random sampling technique was used to select 825 (275 model and 550 non-model) households that had at least one under-five children. Data was collected using pre-tested questionnaire by trained data collectors. A summery descriptive summery statistics and chi-square test was computed to describe the data.Result:In the study 265 model and 529 non-modelhouseholds with at least one under-five childrenwere enrolled the interview, which makes a response rate of $96.2 \%$. Almost all of the respondents were the real mothers of the index child for both groups [264 (99.6\%) model and 528 (99.8\%) non-model households]. Regarding to religion Orthodox was shared more than half of the total study population for both group [167 (63.0\%), model and 332 (62.8\%), non-model households]. Among the study participants 74 (27.9\%) model and 188 (35.5\%) non-model households was Bench by ethnicity.The two weeks diarrhea prevalence in under-fives among model and non-model household were $6.4 \%$ and $25.5 \%$, respectively, which is statistically significant different $[\mathrm{x} 2=41.63, \mathrm{P}<0.01]$.Conclusion: there is significant difference of diarrheal prevalence was observed among children's whose families were model and non-model for health extension programme. Thus encouraging households being model families should be strengthening to reduce childhood diarrhea.
\end{abstract}

Keywords: Prevalence, Childhood, Health Extension, Model and Non-Model Family

\section{Introduction}

\subsection{Background}

In the 1960 s and 1970 s was, for many developing countries, an era of newly won independence from former colonial powers. This independence was accompanied by a passion to provide healthcare, education and other services for the people. Governments moved to establish teaching hospitals for medical \& nursing professionals, with the assistance of donor nations. These tertiary services consumed large budget and were available mostly in urban areas. Healthcare services to the rural majority population were supplied by missionary hospitals and clinics, or by "touring services" from urban hospitals [1].

In 1977, the World Health Assembly (WHA) adopted Primary Health Care (PHC) from China, Tanzania, Sudan and Venezuela. In the following year, international 
Conference Alma-Ata, USSR, declared PHC as the key approach to achieve "health for all by the year 2000" [2]. However, due to lack of staff and essential medicines, civil war, natural disasters, emerging of HIV, lack of political commitment, poor governance and corruption werechallenged the strategy to achieved by the year 2000 . Though, the 2008 World Health Report has made a strong call to all countries to direct their health systems towards the values of PHC reflected in the Alma Ata declaration 30 years ago: social justice and the right to better health for all, participation and solidarity [1].

Ethiopia is one of the signatory countries to implement PHC [3]. The country has a large predominant (84\%) rural residence population with poor access to safe water, housing, sanitation, food and health services [4,5]. In effect, the government introduced a new initiative Health Extension program (HEP) in $2002 / 03$ as a means of providing a comprehensive, universal, equitable and affordable healthcare service for rural population on the base of promotive, preventive and basic curative services. The program has 16 interventional packages focuses on three major areas: environmental health, family health, disease prevention and health education. As a strategy of the program households have been graduated as Model Families after trainedthe packages. Model families are expected to implement the packages and use healthcare services. Currently $25.6 \%$ and $21 \%$ households are graduate's as health extension model families nationally and in the study area, respectively. Yet in Ethiopian, the major health problem is communicable diseases accounts 60-80\% [6].

Childhood mortality rates in general and infant mortality in particular, are often used as broad indicators of social development or as specific indicators of health status. One of the Millennium Development Goaltargetis reduction oftwo-thirds child mortality by 2015[7]. Worldwide diarrheal disease is the second leading cause of death in under-five year'schildren.It is responsible for 1.7 million morbidity and 760, 000 mortality of children every year[8]. In Ethiopia diarrhea kills half million under-five children annually secondary to pneumonia[9].Around $90 \%$ of diarrheal disease occurs due to poor sanitation, lack of access to clean water supply and inadequate personal hygiene [10]. Most of the determinants of diarrhea are included in the health extension intervention programme as packages.

However, there is no quantified evidence whether the strategy of model families in rural health extension program has been made effect on diarrheal occurrence in under-five children or not? Comparison of the two families helps the intervention activities in rural Sheko district particularly and in general nationally either to redirect efforts accordingly. Therefore, the purpose of the study is to assess the prevalence of diarrheal disease in under-five children between health extension model and non-model family in Sheko district rural community.

\subsection{Methods and Subjects}

A community based comparative cross-sectional study was conducted from January 31 to February 29/2012 at Sheko district. Sheko district is located in Bench Maji Zone $577 \mathrm{~km}$ away from Addis Ababa to the Southwest Ethiopia. The district is bordered on the South by Dizi, West by South Sudan, North by Gambela Region, and East by Bench. The healthcare service of the district is rendered through 3 health centers, 23 health posts, and 7 different private owner clinics [11].

Source population was all households with under-five children in Sheko district rural community.Study population definition: Model family- is the household head, which had taken basic training on the 16 health extension packages for 96 hoursby health extension worker and implemented the packages. Non-model family- is the household head, which had not taken basic training on the 16 health extension packageswith under-five children living in randomly sampled kebele of the district rural community.

Sample size was calculated using STATCALC program of EPI INFO statistical software by considering $25.1 \%$ prevalence of two weeks diarrheal disease in under five children(as outcome variable) [12], 95\% confidence interval $\left(Z \alpha_{/ 2}\right), 80 \%$ power and model to non-model household ratio $1: 2$, to detect 2 odds ratio, design effect 2 and $10 \%$ nonresponse rate. Accordingly, the total sample size was 825 ( 275 model and 550 non-model) households with at least one under five-children were included in the study.

The district was stratified by climatic condition in to "Kolla" (tropical zone), "WoynaDega" (subtropical zone) and "Dega" (cool zone) by assuming that occurrence of diarrheal disease varies with climatic zone. Almost $50 \%$ of the kebeles from each climatic condition (strata) was selected randomly using lottery method and the calculated sample size was allocated proportionally to size for both group. Then, households with at least one under-five children were selected using simple random sampling from sampling frame.

Data was collected using adapted structured questionnaire [13, 14]. The questionnaire has two parts. The first part contains socioeconomic factors. Occurrence of diarrhea in under-five children and measure taken was considered in the second section. The questionnaire was first translated into the local language Amharic and back retranslated into English by other person to check its consistency. Moreover, the instruments was pre-tested on a local area with population having similar sociodemographic status on $5 \%$ of the actual sample size, and necessary corrections was made accordingly. Data was collected by trained diploma holder data collectors. Principal investigator and supervisors were checked the data enumeration on daily base.

To be edited, cleaned and analyzed, the collected data was entered into a computer using SPSS version 16.0 software. A summary descriptive statistics and chi-square test was done to describe the data. 
The study was approved by health research and post graduate coordinating office, college of Public health and medical science of Jimma University. Letter of cooperation was obtained from zone health department and district health office.Information sheet about the study purpose, respondent's right and confidentiality was explained and verbal consent from study participant was secured prior the interview.

\section{Result and Discussion}

\subsection{Socio Demographic Characteristics}

In the baseline survey, a total of 2788 eligible households with at least one under-five children (693 model and 2095non-modelfamily) were identified. A total of 825 (275 model and 550 non-model) households with at least one under-five children were planned to participate in the study, out of which 794 (265 model and 529 non-model) were enrolled in the interview, which makes a response rate of $96.2 \%$.
In this study almost all of the respondents were the real mothers of the index child for both groups [264 (99.6\%) model and 528 (99.8\%) non-model households]. Regarding to religion Orthodox was shared more than half of the total study population for both group [167 (63.0\%), model and 332 (62.8\%), non-model households]. Among the study participants $74(27.9 \%)$ model and 188 (35.5\%) non-model households was Bench by ethnicity. Majority of the mothers 260 (98.1\%) model and 515 (97.4\%) non-model mothers occupation were housewife and almost three fourth of the study population were illiterate by both groups [194 (73.2\%) model and $400(75.6 \%)$ non-model households] (Table 1).

Among the interviewed households 175 (66.0\%) model and $382(72.2 \%)$ non-model family size were less than or equal to five. During the data collection time majority of the respondents $204(77.0 \%)$ model and 437 (82.6\%) nonmodel were earned an income less than or equal to 650.00 Ethiopian Birr per month (Table 1).

Table 1.Comparison of socio demographic characteristics among model and non-model households $(n=794)$, Sheko district, Southwest Ethiopia, February 2012

\begin{tabular}{|c|c|c|}
\hline Characteristics & $\begin{array}{l}\text { Model families } \\
(n=265) \\
\text { Number }(\%) \\
\end{array}$ & $\begin{array}{l}\text { Non-model families } \\
(\mathrm{n}=529) \\
\text { Number }(\%)\end{array}$ \\
\hline \multicolumn{3}{|c|}{ Respondent relationship to the index child } \\
\hline Mother & 244(99.6) & $528(99.8)$ \\
\hline Caregiver & $1(0.4)$ & $1(0.2)$ \\
\hline \multicolumn{3}{|l|}{ Age of the respondent } \\
\hline $15-24$ & $98(41.0)$ & $187(35.4)$ \\
\hline $25-34$ & $141(59.0)$ & $300(56.7)$ \\
\hline$>=35$ & $26(9.8)$ & $42(7.9)$ \\
\hline \multicolumn{3}{|c|}{ Marital status of the respondent } \\
\hline Married & $258(97.3)$ & $524(99.1)$ \\
\hline Divorced & $6(2.7)$ & $4(0.9)$ \\
\hline \multicolumn{3}{|c|}{ Ethnicity of the respondent } \\
\hline Bench & $74(27.9)$ & $188(35.5)$ \\
\hline Sheko & $71(26.8)$ & $112(21.2)$ \\
\hline Amhara & $62(23.4)$ & $126(23.8)$ \\
\hline Kefficho & $24(9.1)$ & $39(7.4)$ \\
\hline Sheka & $17(6.4)$ & $24(4.5)$ \\
\hline Others & $17(6.4)$ & $40(7.6)$ \\
\hline \multicolumn{3}{|c|}{ Religion of the respondent } \\
\hline Orthodox & $167(63.0)$ & $332(62.8)$ \\
\hline Muslim & $38(14.3)$ & $62(11.7)$ \\
\hline Protestant & $48(18.2)$ & $110(20.8)$ \\
\hline Others & $12(4.5)$ & $25(4.7)$ \\
\hline \multicolumn{3}{|l|}{ Mothers education } \\
\hline Literate & $71(26.8)$ & $129(24.4)$ \\
\hline Illiterate & $194(73.2)$ & $400(75.6)$ \\
\hline \multicolumn{3}{|l|}{ Mothers occupation } \\
\hline Housewife & $260(98.1)$ & $515(97.4)$ \\
\hline Others & $5(1.9)$ & $17(2.6)$ \\
\hline \multicolumn{3}{|l|}{ Fathers education } \\
\hline Literate & $166(64.3)$ & $384(73.3)$ \\
\hline Illiterate & $92(35.7)$ & $140(26.7)$ \\
\hline \multicolumn{3}{|l|}{ Family size } \\
\hline$<=5$ members & $175(66.0)$ & $382(72.2)$ \\
\hline$>5$ members & $90(34.0)$ & $147(27.8)$ \\
\hline \multicolumn{3}{|l|}{ Monthly income } \\
\hline$>650.00$ Birr & $61(23.0)$ & $92(17.4)$ \\
\hline$<=650.0$ Birr & 204(77.0) & $437(82.6)$ \\
\hline
\end{tabular}




\subsection{Differentials of Childhood Diarrhea among Model and Non-Model Households}

Comparing model and non-model households, a remarkable difference in childhood diarrhea prevalence was observed. The occurrence of diarrheal disease among children's whose families were non-model for the program was $25.5 \%$, which is much more common than children's whose families were model for the program was $6.4 \%$ (Table2). This difference is statistically significant $[\mathrm{x} 2=$ 41.63, $\mathrm{P}<0.01]$. The difference might be attributed to, personal hygiene, sanitation, and water safety measures practiceand knowledge difference acquired from health extension training and demonstration of safety measures.
Diarrhea prevalence also varies by children age group for both model and non-model families, young children age 12-23 months living in non-mode households shared $31.3 \%$ and children age $<6$ months living in model households shared $15.8 \%$, which were more prone to diarrheal disease than children in the other age groups. This might be due to the combined effect of declining level of maternal acquired immunity; the introduction of food or liquid that may be contaminated with pathogens; and direct contact with human and animal excreta when the child starts to crawl[15, 16]. But, the prevalence of childhood bloody diarrhea in both model and non-model family were the same $2.3 \%$ (Table 2).

Table 2.Comparison of two weeks childhood diarrhoea prevalence among model and non-model households (n = 794), Sheko district, Southwest Ethiopia, February 2012

\begin{tabular}{|c|c|c|c|c|c|c|}
\hline \multirow{4}{*}{ Variables } & \multicolumn{6}{|c|}{ Diarrhea in the two weeks preceding the survey } \\
\hline & \multicolumn{3}{|c|}{ Model family } & \multicolumn{3}{|c|}{ Non-model family } \\
\hline & \multicolumn{2}{|c|}{ Prevalence of diarrhea (\%) } & \multirow[b]{2}{*}{ Children(No.) } & \multicolumn{2}{|c|}{ Prevalence of diarrhea (\%) } & \multirow[b]{2}{*}{ Children(No.) } \\
\hline & All & Bloody & & All & Bloody & \\
\hline \multicolumn{7}{|l|}{ Child age in months } \\
\hline$<6$ & 15.8 & 0.0 & 19 & 10.5 & 0.0 & 38 \\
\hline $6-11$ & 5.2 & 1.7 & 58 & 30.2 & 3.1 & 96 \\
\hline $12-23$ & 5.6 & 3.3 & 90 & 31.3 & 3.2 & 217 \\
\hline $24-35$ & 11.9 & 2.4 & 42 & 20.7 & 2.2 & 87 \\
\hline $36-47$ & 0.0 & 0.0 & 26 & 19.4 & 0.0 & 67 \\
\hline $48-59$ & 3.3 & 3.3 & 30 & 12.5 & 0.0 & 24 \\
\hline \multicolumn{7}{|l|}{ Diarrhea prevalence } \\
\hline Two weeks & 6.4 & 2.3 & 265 & 25.5 & 2.3 & 529 \\
\hline
\end{tabular}

\section{Conclusion}

A remarkable prevalence difference of diarrhea in underfive children among health extensionmodel and non-model family was observed. Children whose families were nonmodel for health extension program were more prone todevelop diarrhea than children whose families were model for the program. Cognizant of this fact, we recommend that the strategy of being model families should be strengthen to reduce childhood diarrhea.

\section{Competing Interests}

The authors declare that they have no competing interests.

\section{Authors' contributions}

TG designed the study and drafted the manuscript. MT participated in the design of the study and in the manuscript draft. WK participated in the design of the study and statistical analysis. All authors read and approved the final manuscript version submitted for publication.

\section{Acknowledgment}

We extend our appreciation to data collectors, supervisors and the study participants for their cooperation and also we would like to thank Sheko district health office staffs especially health extension workers in providing the necessary information. The study was funded by Jimma University College of Public Health and Medical Science.

\section{References}

[1] John J, Richard T. Health for all beyond 2000:The Demise of the Alma-Ata Declaration and Primary Health Care in Developing countries. Global health. 2003 Jan 6;178:17 19.

[2] WHO. Global strategy for health for all by the year 2000 . 1981.

[3] Kitaw Y, Teka E, Meche H. The Evolution of Public Health in Ethiopia. 2005;

[4] Argaw H. The Health Extension Programme of Ethiopia: Summary of Concepts, progress, Achievements and Challenges. WHO; 2007. 
[5] UNICEF. Ethiopia Newsletter, sanitation issue JulySeptember 2004 Vol. 6, No3. World Vision-UNICEF. 2004;6(3).

[6] Argaw H. The Health Extension Programme of Ethiopia: Summary of Concepts, Progress, Achievements and Challenges. WHO; 2007.

[7] Central Statistical Agency. Children's Health and Nutritional Status. Children's Health aEthiopia Demographic and Health Survey. Addis Ababa, Ethiopia; 2012. p. 3-24.

[8] WHO. Diarrheal disease key facts [http://www.who.int/mediacentre/factsheets/fs330/en/].

[9] MOH.Health sector development program IV, 2010 - 2014. $2010 ; 59$.

[10] UNICEF. Sanitation issue. Ethiopian Newsletter. 6th ed. Addis Ababa; 2004;

[11] Health office. Sheko district Annual report. Sheko; 2011.

[12] Central Statistical Agency. Ethiopia Demographic and Health Survey Addis Ababa, Ethiopia; 2005
[13] WHO/UNICEF. Core questions on drinking water and sanitation for household surveys. Geneva, Switzerland: WHO Press; 2006.

[14] MOH. Report on the Assessment of Factors Contributing to and Affecting Performance of Health Extension Workers in Selected Woredas of Amhara National Regional State and Southern Nation, Nationalities and People's Region [http://isearch.avg.com/search? $\mathrm{q}=\mathrm{MOH}+\mathrm{AND}+$ Report+on $+\mathrm{t}$ he + Assessment + of + Factors + Contributing + to + and + Affectin $\mathrm{g}+$ Performance + of + Health + Extension + Workers + in + Selecte $\mathrm{d}+$ Woredas $+\&$ sap $=\mathrm{hp} \&$ snd $=\mathrm{hdr} \&$ sap_acp $=0]$. Addis Ababa, Ethiopia; 2008].

[15] Teklemariam S, Getaneh T, \& Bekele F. Environmental determinants of diarrhoea morbidity in under-five children, Keffa-Sheka Zone, Southwest Ethiopia. Medical journal. 2000;38(1):27 -34.

[16] Getaneh T. Diarrhoea morbidity in urban area of Southwest Ethiopia. East African Medical Journal. 1997;74(8):491 494. 